\title{
Intelectuais e a transição democrática no México: globalização e modernização como discursos $(1988-2000)^{*}$
}

\author{
Intellectuals and the Democratic \\ Transition in Mexico: Globalization and \\ Modernization as Discourses (1988-2000)
}

Los intelectuales y la transición democrática en México: globalización y modernización como discursos (1988-2000)

\author{
José Antonio Ferreira da Silva Júnior** \\ (D) https://orcid.org/0000-0002-4123-2487 \\ Universidade Estadual de Campinas, Brasil / \\ Rice University, Estados Unidos \\ joseafsj@gmail.com
}

Resumo: O presente artigo tem por objetivo analisar debates e discussões intelectuais no contexto das reformas neoliberais entre os anos 1980 e 1990 no México. $O$ argumento central é que a globalização atuou também na esfera

* Financiado por: Fundação de Amparo à Pesquisa do Estado de São Paulo (FAPESP) sob o projeto "A construção do México pós-nacional: intelectuais, NAFTA e a questão da identidade nacional".

** Doutorando Unicamp. Ph. D. Candidate Rice University.

cómo citAR: Silva Júnior, J. A. Ferreira da (2021). Intelectuais e a transição democrática no México: globalização e modernização como discursos (1988-2000). Secuencia (109), e1797. Dor: https://doi.org/10.18234/ secuencia.v0i109.1797 
cultural e simbólica através de discursos que se efetivaram na imprensa, onde intelectuais mexicanos discutiram as transformações de seu presente. A análise de revistas culturais publicadas no período revela uma ampla diversidade de posições tomadas pela intelectualidade para interpretar e significar estes processos, utilizando argumentos e ideias para debater e construir explicações para aquela conjuntura. Temas como globalização, democracia e "modernização" são aqui analisados com maior atenção, revelando como intelectuais mobilizaram conceitos para justificar e fundamentar seus argumentos. Inspirado pela história política e intelectual, busco compreender como estas operações discursivas estão conectadas com o contexto político do processo de transição democrática no México.

Palavras-chave: intelectuais; história intelectual; transição; revistas culturais; globalização.

Abstract: This article seeks to analyze debates and intellectual discussions in the context of neoliberal reforms between the 1980s and 1990s in Mexico. The central argument is that globalization also acted in the cultural and symbolic sphere through discourses that took place in the press, where Mexican intellectuals debated the transformations of their present. The analysis of the cultural journals published during this period reveals a wide diversity of positions taken by intellectuals to interpret and signify these processes, using arguments and ideas to debate and construct explanations of this situation. Issues such as globalization, democracy and "modernization" are analyzed here in greater detail, showing how intellectuals mobilized concepts to justify and substantiate their arguments. Drawing inspiration from political and intellectual history, I attempt to show how these discursive operations relate to the political context of the democratic transition process in Mexico.

Keywords: intellectuals; intellectual history; transition; cultural journals; globalization.

Resumen: Este artículo tiene como objetivo analizar debates y discusiones intelectuales en el contexto de las reformas neoliberales entre las décadas de 1980 y 1990 en México. El argumento central es que la globalización también actuó 
en el ámbito cultural y simbólico a través de discursos que tuvieron lugar en la prensa, donde intelectuales mexicanos debatieron sobre las transformaciones de su presente. El análisis de las revistas culturales publicadas en el periodo revela una amplia diversidad de posiciones tomadas por los intelectuales para interpretar y significar estos procesos, utilizando argumentos e ideas para debatir y construir explicaciones de esa situación. Temas como la globalización, la democracia y la "modernización" se analizan aquí con mayor atención, revelando cómo los intelectuales movilizaron conceptos para justificar y fundamentar sus argumentos. Inspirándome en la historia política e intelectual, busco comprender cómo estas operaciones discursivas están conectadas con el contexto político del proceso de transición democrática en México.

Palabras clave: intelectuales; historia intelectual; transición; revistas culturales; globalización.

Recibido: 22 de octubre de 2019 Aceptado: 29 de enero de 2020

Publicado: 27 de enero de 2021

\title{
INTRODUÇÃO
}

\begin{abstract}
A longo do século xx, a política mexicana foi marcada pelo domínio do 1 Partido Revolucionario Institucional (PRI) que venceu as eleições presidenciais desde os anos 1930 (quando ainda era o Partido Nacional Revolucionario [1929-1938] e o Partido de la Revolución Mexicana [1938-1946]) até 2000, ano em que foi derrotado nas urnas pelo Partido Acción Nacional (PAN), com a candidatura de Vicente Fox. Este fato, normalmente visto como a derrota do modelo priista, na verdade, revela a concretização de um processo político, econômico e social que remonta aos anos 1980. Uma profunda crise econômica nesta década levou o México a uma maior aproximação com as políticas neoliberais dos Estados Unidos da América (EUA) que se concretizaram ao longo dos anos 1990 em reformas políticas, eleitorais e econômicas, entre elas a assinatura do NAfTA (North American Free Trade Agreement, em inglês, ou TLCAN - Tratado de Libre Comercio de América del Norte-em espanhol), em 1994. Estas reformas estão inseridas numa série de medidas neoliberais colocadas em prática nos últimos governos priistas do século xx (Miguel de la
\end{abstract}


Madrid, 1982-1988, Carlos Salinas, 1988-1994 e Ernesto Zedillo, 1994-2000) e foram amplamente discutidas na imprensa mexicana, principalmente porque sinalizavam o fim de políticas sociais mantidas por várias décadas pelo PRI.

Esta pesquisa busca abordar a construção discursiva de conceitos em torno dos temas da globalização e do neoliberalismo. Tais discursos foram produzidos por intelectuais e circulados em revistas culturais do período. Deste modo, esta análise foca-se no contexto dos últimos anos da transição democrática no México, ${ }^{1}$ quando o processo de globalização ${ }^{2}$ estava sendo debatido publicamente na imprensa através de textos e artigos que desenvolviam e embasavam noções, ideias, argumentos e opiniões. Assim, minha atenção recai sobre termos específicos que foram empregados pela intelectualidade mexicana e que, como conceitos e categorias de explicação, possuem distintas definições de acordo com os usos e interesses dos interlocutores destes debates. Os intelectuais mexicanos que publicavam nas revistas aqui estudadas envolveram-se diretamente na esfera pública como atores políticos ao tomar posições e escolher lados enquanto discutiam os processos que se desenvolviam na economia nacional e internacional naquele momento. ${ }^{3}$ Bus-

${ }^{1}$ A transição democrática mexicana é um período aproximadamente compreendido entre o fim dos anos 1970 e o fim dos anos 1990. Durante estas décadas, ocorreram mudanças legislativas e reformas políticas que visavam transformar o sistema político mexicano para possibilitar maior participação e competição política, bem como a criação de mecanismos institucionais que garantissem eleições mais transparentes e a existência de espaço democrático para a oposição aos governos do PRI. Marcos temporais mais precisos estabelecem o início da transição em 1977, ano em que a câmara de deputados foi aberta à representantes da oposição, e sua conclusão em 1997, quando pela primeira vez os partidos de oposição ao PRI ganharam a maioria na câmara e o governo do Distrito Federal. Ainda é muito debatido o alcance e a eficiência desta transição em relação à transparência das eleições e à participação democrática da população mexicana após o ano 2000 (Bartra, 2013; Woldenberg, 2012).

${ }^{2}$ Por globalização mexicana me refiro a um período de reformas econômicas com características específicas ligadas à liberalização do comércio, à abertura ao mercado internacional e à adoção de medidas de austeridade na economia nacional. Estas reformas aconteceram no México desde o governo de Miguel de la Madrid, no início dos anos 1980, e se estenderam pelos governos seguintes (Clavijo y Valdivieso, 2000). Embora o termo "globalização" tenha outras definições mais amplas, optamos neste texto por usá-lo como referência a este processo de adoção do neoliberalismo no México nas últimas décadas do século xx, enfatizando a perspectiva de que o neoliberalismo se desenvolve como política econômica do capitalismo global (Bonanno, Martínez y Aboites, 2016).

${ }_{3}^{3}$ Considero como intelectuais neste período todos os profissionais ligados à produção $\mathrm{e}$ mediação de elementos culturais na sociedade mexicana. A discussão historiográfica sobre a definição do intelectual como sujeito histórico e ator político também envolve a ideia de compromisso e engajamento com causas de sua sociedade. Por isso, intelectuais buscam espaços de 
cando compreender os principais artefatos discursivos desenvolvidos neste período da transição mexicana, a história intelectual e a história política nos possibilitam uma abordagem dos intelectuais e seus textos como objetos de estudo que nos permitem ampliar a interpretação da chamada "modernização" que teria ocorrido neste período no país. ${ }^{4}$

\section{A DÉCADA DE 1980 E 1990: CRISES E REFORMAS}

As crises enfrentadas pelo México no fim dos anos 1970 e a partir de 1982, quando foi declarada a moratória da dívida externa, deixaram visível o esgotamento do modelo econômico praticado até então, baseado na exportação do petróleo. O PRI, que desde o Massacre de Tlatelolco, em 1968, enfrentava uma crise de legitimidade e afirmação, passou por reconfigurações internas que abriram espaço para dirigentes com uma perspectiva sobre o neoliberalismo distinta das tradicionais leituras marxistas e estruturalistas que caracterizavam a concepção priista até então. Neste contexto, o neoliberalismo ganhou espaço nas políticas econômicas do partido através de tecnocratas (em sua maioria, economistas que se formaram ou se especializaram nas universidades dos Estados Unidos de América e da Europa) que se tornaram influentes e passaram a orientar as medidas de austeridade nacional e corte de gastos públicos (Babb, 2001, pp. 171-198; Sheppard, 2016, pp. 74-79).

A ascensão destas concepções econômicas no seio do partido causou uma ruptura entre as diferentes alas que o compunham. A oposição mais incisiva ao PRI, nos anos 1980, partiu justamente de um dissidente do partido, Cuauhtémoc Cárdenas, que fundou o que viria a ser o Partido de la Revolu-

expressão que lhe permitem a efetivação de sua ação política por meio de práticas culturais. A publicação de textos e o trabalho editorial nas revistas aqui estudadas são consideradas práticas intelectuais porque permitem que estes autores participem dos debates políticos de seu presente numa esfera pública entre seus pares, mobilizando o cultural num esforço de convencimento, explicação e crítica na sociedade (Camp, 1981; Castillo y Stuart, 2014; Sirinelli, 2003).

4 "Modernização" será utilizado ao longo deste texto sob uma perspectiva crítica, por isso entre aspas. $O$ conceito foi amplamente utilizado pelos intelectuais mexicanos nas publicações aqui analisadas para se referir às reformas econômicas e políticas dos anos 1980 e 1990, mas optei por usar as aspas de forma a não reproduzir a ideia de modernidade como algo essencialmente positivo. As reformas que se processaram no país com o objetivo de abertura econômica e política também produziram impactos negativos e os próprios intelectuais aqui estudados, como veremos, criticam o uso vazio deste conceito que busca naturalizar o neoliberalismo como oposição a um México "atrasado", "ultrapassado” e "subdesenvolvido” (Monsiváis, 1990). 
ción Democrática (PRD). Nas eleições presidenciais de 1988, sua candidatura organizou-se em torno da ideia de evitar a falência dos princípios revolucionários da Constituição de 1917 e de recuperar os direitos que estavam sendo ameaçados pela administração neoliberal do PRI. Cárdenas foi derrotado nas urnas por Carlos Salinas, em meio a escândalos de fraude eleitoral.

O governo de Salinas foi marcado pela forte orientação neoliberal enquanto tentava promover a imagem de uma "revolução realista", ou seja, um Estado revolucionário que adaptava os objetivos sociais da revolução à necessidade de medidas de austeridade que o momento de crise requeria. Desta forma, os compromissos do governo para manter princípios revolucionários, como a reforma agrária e os subsídios estatais, por exemplo, passaram a ser revistos e interpretados por dirigentes políticos como impraticáveis frente à crise econômica (Sheppard, 2016, pp. 87-90). Cada vez mais, ficou clara a fratura entre o nacionalismo revolucionário e as práticas neoliberais no discurso oficial do PRI. A solução encontrada foi o liberalismo social como uma estratégia do governo salinista para reconfigurar a relação entre Estado e sociedade e conter o desgaste que o partido vinha sofrendo por conta das políticas econômicas neoliberais que atacavam as garantias sociais fomentadas pelas Constituição de 1917. Os investimentos em programas sociais, como o Pronasol (Programa Nacional de Solidaridad) e o Procampo (Programa de Apoyos Directos al Campo), e em instituições culturais, como o ConACULTA (Consejo Nacional para la Cultura y las Artes), se deram neste contexto em que o Estado, ainda que dedicado às reformas neoliberais, buscava legitimidade ao garantir justiça social e igualdade (Mize y Swords, 2011, p. 194; Sheppard, 2016, pp. 154-157).

De fato, as reformas econômicas intensificaram-se neste período, mas foram acompanhadas de investimentos em políticas sociais e a formação de programas de combate à pobreza nas zonas urbanas e rurais como forma de combater os efeitos negativos das medidas de austeridade (Dion, 2009, p. 66). Mais do que uma forma de legitimar o PRI, estes programas têm a ver com os impactos das políticas neoliberais na vida das classes trabalhadoras do país. A competição política que se intensificava nestes anos nas eleições estaduais e municipais entre o PRI, O PRD e o PAN, levou a um quadro no qual os programas de previdência e seguro social foram reduzidos, enquanto a assistência social se expandia. Estes processos mostram como os efeitos da globalização neoliberal estão intimamente conectados com o processo de transição democrática e a competição eleitoral no México nos anos 1990. A cientista políti- 
ca Michelle Dion (2009, pp. 76-78) demonstra que a expansão da assistência social a grupos rurais e pobres das cidades está conectada com a redução do seguro social dirigido a trabalhadores formais do setor público e privado. Isto se explica pelo fato de que as reformas políticas possibilitaram maior competição e mobilizou o eleitorado entre distintos interesses representados no crescimento dos partidos opositores ao PRI, mas este processo não se traduziu em participação popular direta. Esta nova capacidade política, no entanto, foi explorada para garantir apoio político de eleitores destes setores da sociedade que somente teriam acesso ao estado de bem-estar através das políticas de assistência social porque, em sua grande maioria, eram trabalhadores informais.

Nos anos 1990, as consequências sociais destas reformas já eram visíveis e análises críticas sobre os rumos que tomava o processo apareciam nestas publicações que serão analisadas mais adiante. $O$ discurso oficial do governo era de que as transformações econômicas eram imprescindíveis para a preparação do México para a economia internacional, que se tornava cada vez mais dinâmica e global. O que é incontestável, no entanto, é que estas reformas na política, economia e sociedade demonstraram que o PRI se afastava do modelo tradicional de governo comprometido a garantir os direitos dos cidadãos (Sheppard, 2016, pp. 143-154).

\section{AS REVISTAS E A HISTÓRIA POLÍTICA E INTELECTUAL}

Diversas publicações deram espaço para textos e artigos sobre os temas em torno da globalização. Neste trabalho, tomei como fonte revistas que participaram destes debates como suporte material para os discursos produzidos pela intelectualidade mexicana do período. Revista de la Universidad de México, Nexos, Vuelta e Letras Libres são publicações que circularam no México nos anos 1980 e 1990 e que trouxeram em suas páginas os artigos que aqui analiso dentre tantos outros acerca dos mais variados temas e conceitos neste contexto. Várias outras publicações também participaram destes debates sobre a globalização e publicaram textos que fizeram parte da discussão sobre as reformas mexicanas no período. A escolha recaiu sobre estas três publicações justamente pelo prestígio que congregam junto à opinião pública mexicana e pela proeminência que têm no campo intelectual mexicano até hoje. Outro dado importante é que, embora cada revista tenha sido fundada por grupos intelectuais distintos e em contextos específicos, seus editoriais alcançaram 
reconhecimento nacional e internacional naquele período como fórum de discussão da situação mexicana. Quando a questão da globalização e das reformas começou a ser debatido na esfera pública foram estas revistas que pautaram a discussão e foram suporte e referência central para os intelectuais do período.

A Revista de la Universidad de México é uma das publicações mais longevas no México. Sua origem remonta ao processo de luta pela autonomia da Universidad Nacional Autónoma de México (UnAm), ocorrido em 1929. A revista, que teve o primeiro número publicado em novembro de 1930, dava continuidade ao objetivo do Boletín de la Universidad de México de servir como meio de comunicação da comunidade acadêmica (Sánchez, 2013). Em 1946, após outro processo de reorganização, a Revista de la Universidad de México tornou-se uma publicação mais acadêmica e literária, deixando um pouco de lado a função de ser um informativo entre os estudantes e buscando atingir o público mais amplo, não ligado à universidade. Assim, passou a publicar textos que buscavam popularizar o conhecimento acadêmico, colocando-se em maior contato com a sociedade mexicana do período: "Universidad de México será un diáfano reflejo de las inquietudes culturales del país y un vehículo puesto de modo permanente al servicio de la mejor coordinación y logro de tales esperanzas" (Justificación, 1946, p. 1).

Desde então, a publicação converteu-se em um importante referencial da cultura mexicana, publicando textos de distintas gerações de intelectuais e tornando-se um espaço tradicional de contato entre as culturas acadêmicas e populares, sendo um ponto de observação privilegiado da história intelectual do país. Segundo Ignacio Solares (2010, p. 82), entre seus diretores se destaca o intelectual Jaime García Terrés, que esteve à frente da revista entre 1953 e 1965, um período no qual a UNAM era vista como um espaço livre da censura imposta pelo governo a outros órgãos e periódicos. García Terrés, então, utilizando-se desta prerrogativa, construiu a Revista de la Universidad de México como um espaço de afirmação da cultura mexicana contemporânea, contando com a colaboração de escritores e artistas e promovendo uma cultura intelectual que consagraria esta revista como uma das publicações culturais mais importantes e estáveis do México pelo resto do século xx (Solares, 2010, pp. 84-85). Respeitando esta vocação de dar espaço para debate e circulação das ideias dos principais nomes da intelligentsia mexicana, a Revista de la Universidad de México não renuncia a participar das discussões e desafios que se colocam ao México nos anos 1980 e 1990. Como é possível perceber pelos tex- 
tos que serão analisados na próxima seção, a revista colocou-se como foro de compreensão e debate sobre a globalização e o neoliberalismo neste período, servindo de veículo de discursos e ideias de diversos intelectuais que participaram assim ativamente dos processos políticos do país.

Os intelectuais mexicanos também encontraram espaços de expressão em outras publicações, como as revistas Vuelta e Letras Libres. Vuelta surgiu em 1976, após o fechamento da revista Plural que funcionava como suplemento cultural do jornal Excélsior. Naquele ano, após publicar uma série de críticas ao então presidente do México, Luis Echeverría Álvarez, o diretor Julio Scherer García e o conselho editorial de Excélsior foram afastados. Octavio Paz, que encabeçava Plural, renunciou a seu cargo em solidariedade a Scherer junto com o conselho da revista, o que levou ao fim do suplemento. Poucos meses depois, Paz e seus colaboradores fundavam a revista Vuelta como uma continuação de Plural, uma publicação voltada a promover a literatura hispano-americana e a cultura mexicana contemporâneas. Muito ligada à figura de Octavio Paz, Vuelta definiu-se como um projeto editorial baseado na ideia de independência e crítica. Paz por diversas vezes destacou a importância da independência da publicação em relação ao poder político justamente como condição que garantisse a liberdade de crítica, a principal função da revista segundo ele. Mais do que uma revista de crítica literária, Vuelta constituiu-se, então, como uma publicação ligada aos posicionamentos políticos de Paz e seus seguidores, que se identificavam como liberais e avessos aos compromissos políticos, críticos principalmente da esquerda marxista mexicana (Flores, 2010, pp. 508-513). A revista teve seu fim em 1998, porém Enrique Krauze, que atuou como secretário de redação e subdiretor de Vuelta, fundou, no ano seguinte, Letras Libres. Esta revista passou a ocupar o espaço deixado entre os intelectuais liberais e teve como colaboradores alguns membros do grupo Vuelta.

A revista Nexos foi fundada em 1978, sob direção do historiador Enrique Florescano. Membro do departamento de história do Instituto Nacional de Antropología e Historia no período, Florescano organizou uma série de seminários que reunia acadêmicos de diversas áreas em torno das discussões sobre os problemas do presente mexicano. Destas reuniões surgiu o interesse em criar uma publicação que fosse espaço de difusão para o conhecimento acadêmico e científico debaterem as questões da conjuntura política e social do México. Com um conselho editorial organizado em torno de diferentes áreas do conhecimento, Nexos se propunha a oferecer interpretações e leituras que pudessem enriquecer a percepção dos leitores em torno aos problemas 
mais variados que o país estava enfrentando nas questões culturais, políticas e sociais (Concheiro, Rodríguez y Ruiz, 2018, pp. 17-20). Entre os diretores de Nexos, além de Florescano, estão renomados intelectuais como Héctor Aguilar Camín, Luis Miguel Aguilar e José Woldenberg. A revista sempre se posicionou como alinhada à socialdemocracia, o que fomenta certa rivalidade com o grupo da revista Vuelta, mais alinhada ao liberalismo. De acordo com Gallegos Cruz (2018, p. 76), "Nexos nace como una revista antitética de Vuelta, con quien busca competir por el liderazgo de la comunidad intelectual".

As duas publicações colocavam-se com frequência em lados opostos em seus posicionamentos e debates ao longo das décadas de 1980 e 1990. O atrito mais famoso entre as revistas se deu entre 1990 e 1992, quando a queda da União Soviética motivou a discussão no México sobre as transformações e crises em escala global. Em 1990, Paz e o grupo Vuelta convocaram intelectuais para a realização de um encontro chamado El Siglo XX: la Experiencia de la Libertad. O tom geral dos participantes deste evento foi o de valorizar a queda do comunismo como um triunfo da democracia capitalista, destacando a importância do mercado para a liberdade individual e econômica em relação ao Estado. Dois anos depois do evento de Paz, o grupo Nexos organizou um colóquio sob o título de "Los grandes cambios de nuestro tempo: la situación internacional, América Latina y México". Conhecido como Coloquio de Invierno, este evento debateu a conjuntura mundial e mexicana de inícios dos anos 1990, e as discussões aí realizadas criticavam a perspectiva liberal, ressaltando a importância da democracia como forma de produzir um Estado e um governo capazes de garantir justiça social. Além das discordâncias ideológicas, este evento ligado à revista Nexos gerou críticas de Octavio Paz e seus colaboradores por conta de ter recebido patrocínio de órgãos estatais, como o ConAculta (Gallegos Cruz, 2018, pp. 115-124).

Desta forma, ao discutir cultura, ciência, arte, política e sociedade a partir das intervenções e interpretações que intelectuais submetiam para publicação, Revista de la Universidad de México, Vuelta, Letras Libres e Nexos criaram e fizeram parte de um espaço público de construção e circulação de discursos sobre a realidade mexicana e as transformações pelas quais o país passava. Assim, defendo a importância de percebermos a formação de uma linguagem política-intelectual específica neste contexto de globalização no México, relacionando os discursos analisados nestes textos com um referencial conceitual mais amplo. O historiador Jean-François Sirinelli (2003), ao propor o estudo dos intelectuais e suas obras como objetos da história polí- 
tica, ressaltou a importância de se "tentar destrinchar a questão das relações entre as ideologias produzidas ou veiculadas pelos intelectuais e cultura política de sua época" (p. 261). Deste modo, quero argumentar que os debates a serem analisados não se deram apenas como um diálogo direto entre revistas e autores. É essencial compreender que cada texto mobiliza ideias e argumentos que estão fazendo referência aos elementos discursivos e simbólicos elaborados no campo cultural e intelectual mexicano. Cada artigo publicado pode ser compreendido como capaz de refletir e, ao mesmo tempo, influenciar as transformações políticas e sociais de seu presente no México.

John G. A. Pocock, historiador do pensamento político, usa os conceitos de langue e parole para explicar a relação que os discursos efetivados dentro de um contexto político têm entre si, não só pela referência direta, mas pela sua própria formulação. Este princípio, para Pocock (2003), é essencial para o estudo da história política e intelectual:

O historiador do discurso político [...] investe seu tempo aprendendo as "linguagens", idiomas, retóricas ou paradigmas em que tal discurso se realizou, ao mesmo tempo estudando os atos de enunciação que foram emitidos nessas "linguagens", ou na linguagem formada de um composto delas. [...] O historiador deve mover-se de langue para parole, do aprender as linguagens para o determinar os atos de enunciação que foram efetuados "dentro" delas (p. 66).

Para este autor, então, as linguagens políticas -que podem ser "idiomas, retóricas, maneiras de falar sobre política, jogos de linguagem distinguíveis, cada qual podendo ter seu vocabulário, regras, precondições, implicações, tom e estilo" (Pocock, 2003, p. 65) - são uma importante instância de análise da configuração cultural e política de dado contexto histórico. Deste modo, o autor define parole como cada discurso efetivado, cada argumento criado ou conceito mobilizado pelos intelectuais em seus textos. A langue é a linguagem política mais ampla, o arcabouço retórico ou referencial conceitual que dá sentido e significado para cada parole, cada discurso elaborado pelos intelectuais ao construir seus textos e tomar parte nos debates públicos de sua conjuntura (Pocock, 2003, pp. 73-74). O que quero ressaltar é que os textos aqui analisados trazem ideias e argumentos que superam suas páginas e seu momento de publicação. Os autores estão dialogando com um contexto discursivo mais amplo entendido como a linguagem política mexicana deste período de globalização e transição democrática. As revistas culturais aqui es- 
tudadas são tomadas como espaços de enunciação e expressão dos intelectuais que se posicionaram nestas discussões através de seus textos, produzindo e difundindo o ideário político mexicano do fim do século xx.

\section{GLOBALIZAÇÃO: UM DISCURSO DE INEVITABILIDADE ${ }^{5}$}

Inicialmente, os textos sobre a globalização começaram a surgir nas revistas estudadas a partir do fim dos anos 1980. As análises sobre este processo, neste momento, eram bastante ligadas à economia e interpretavam a globalização como um desenvolvimento do contexto de crise da URSS e fim da guerra fria. A explicação do fenômeno da globalização pautou-se, então, na ideia da falência do modelo econômico anterior que, se entre as décadas de 1950 e 1970, foi responsável por gerar prosperidade no cenário instável do pós-guerra, já nos anos 1980 estava esgotado pelas crises de energia da década anterior e pela instabilidade no comércio mundial. As diversas políticas econômicas adotadas pelos Estados Unidos de América, Japão e países da Europa ocidental são apresentadas como elementos que conformam este novo modelo da economia global na qual os limites do Estado nacional já não são mais válidos. A perspectiva assumida pelos intelectuais nestes textos é de que o fim da bipolaridade mundial e o surgimento de uma ordem multipolar criaram um cenário de crise para os Estados Unidos, que enfrentavam concorrência na liderança da economia internacional. Utilizando os conceitos de desenvolvimento/subdesenvolvimento, Primeiro Mundo/Terceiro Mundo, Norte/Sul, estes autores reproduziram a ideia de globalização como um desenvolvimento a partir da Teoria da Dependência, sendo uma nova etapa no capitalismo mundial imposta pelos países industrializados que tentavam se adequar à nova ordem mundial, como fica explícito neste trecho de um artigo de Antonio Gutiérrez Pérez, ${ }^{6}$ de 1991:

La globalización de los procesos económicos se refiere a una nueva fase del desarrollo capitalista, caracterizada por la desregulación de los mercados y la

${ }^{5}$ Como as revistas foram acessadas em suas hemerotecas digitais, muitos dos artigos não têm numeração nas páginas. Nestes casos, as páginas indicadas em itálico se referem à numeração do arquivo PDF disponível nos sites.

${ }^{6}$ Gutiérrez Pérez é graduado em Sociologia pela UnAm e recebeu seu doutorado em Economia na Universidade de Paris, em 1984. 
privatización de las economías. Estos procesos responden fundamentalmente a las necesidades de los capitales de los países industriales, especialmente estadounidenses, de redefinir y recrear sus espacios de valorización y acumulación (Gutiérrez Pérez, 1991, p. 13).

Entre as consequências para os países em desenvolvimento, os textos destacam as crises da dívida externa na América Latina. A globalização era entendida, então, como a origem de novos problemas econômicos para o México, porém também foi vista e discutida como a solução para pautar o desenvolvimento da economia e da sociedade mexicana no período. As concepções neoliberais foram amplamente utilizadas nestas publicações para criticar as políticas econômicas do país e circularam nestes textos como única proposta capaz de superar a crise e adequar o México às exigências do mercado globalizado. Conceitos e explicações que surgem nestes artigos, como o papel do Estado na economia de mercado ou a importância das privatizações, dizem respeito a teorias clássicas de economistas que discutiram o desenvolvimento do neoliberalismo no século xx, como Friedrich August von Hayek ou Milton Friedman (Bonanno, Martínez y Aboites, 2016, pp. 45-60). Baseando-se nestas ideias, o neoliberalismo foi apresentado nestas revistas em termos de projeto de desenvolvimento econômico que seria capaz de criar condições sociais mais justas no México. Outros artigos, como veremos mais adiante, partiram de uma perspectiva mais crítica em relação às consequências da globalização neoliberal.

Um texto de Luis Rubio, ${ }^{7}$ publicado na edição de setembro de 1994 de Nexos, é significativo de como foi empreendida a defesa dos ideais da globalização neoliberal como projeto econômico para o país. Segundo os argumentos do autor, neste contexto, a economia internacional seria o parâmetro que define as prioridades da economia nacional mexicana, já que esta seria sua única possibilidade de desenvolvimento: "hoy en día ninguna economía puede crecer sin participar activamente en esos procesos porque la economía internacional ya no es la suma de muchas naciones, sino un proceso que interconecta las economías nacionales en una búsqueda constante de eficiencias y

${ }^{7}$ Luis Rubio tem doutorado em Ciências Políticas pela Brandeis University (1983). Atualmente, é presidente do Consejo Mexicano de Asuntos Internacionales (CoMEXI). No momento da publicação deste texto, era diretor do Centro de Investigación para el Desarrollo (CIDAC) e comentarista de política e economia na imprensa periódica. Foi assessor da Secretaria da Fazenda no início dos anos 1980, durante o governo de José López Portillo. 
ventajas comparativas" (Rubio, 1994, p. 2). As empresas privadas, de grande ou pequeno porte, seriam a garantia do desenvolvimento do país já que são fonte de emprego e propiciam maiores níveis de qualidade de vida da população. Rubio afirma que a importância da economia interna, então, reside na capacidade de gerar empresas capazes de competir no mercado internacional.

O papel do Estado na economia, para o autor, deve ser mínimo e apenas atuar para garantir esse ambiente de pleno desenvolvimento das empresas privadas. Segundo sua argumentação, a intervenção do Estado mexicano na economia durante o século xx fez diminuir o investimento privado nos setores produtivos do país, aumentando os gastos estatais e a inflação, criando um cenário difícil para o funcionamento das empresas nacionais, que não foram estimuladas pela competição em um mercado livre (Rubio, 1994, pp. 1-2).

Além de elaborar seus argumentos de acordo com a ideologia neoliberal mais conservadora, capaz de submeter os distintos setores da sociedade aos interesses do capital privado, Rubio também comenta em seu artigo sobre o levante zapatista de Chiapas, em 1994. Segundo o autor, o movimento de Chiapas é anacrônico e uma demonstração de como posições retrógradas ainda existem e ameaçam o desenvolvimento Mexicano. Também afirma que é uma luta apegada ao velho sistema do PRI de fechar o país ao comércio global, negando a "modernidade" em nome da manutenção de subsídios que apenas causam atraso à economia nacional. O autor é enfático em sua crítica:

Chiapas resulta ser el gran evento que reúne a los dinosaurios empresariales, priistas, corporativos, de los partidos y demás a celebrar que finalmente tenemos una excusa para no procurar la modernidad. En esa perspectiva, los levantados hicieron ver que nuestros rezagos son más importantes que nuestro potencial. Chiapas sin duda evidenció los rezagos, pero no hizo sino confirmar que nuestra única salida es el cambio económico. Si algo, Chiapas indica que el problema de la reforma es que no se han cambiado suficientes cosas, que falta demasiado y que el tiempo se agota (Rubio, 1994, pp. 11-12).

Este trecho destaca a visão de que a reforma neoliberal estaria incompleta e, segundo o autor, deveria ser intensificada para que o México se torne um país desenvolvido. Também fica clara a ideia de que a globalização e as reformas empreendidas são a única solução para os problemas mexicanos. Rubio já havia lançado esta ideia em outro momento do artigo: "Los cambios económicos de los últimos años eran necesarios e inevitables; pueden gustar- 
nos o no, pero constituían la única posibilidad de recobrar el crecimiento económico y, por ello, eran imperativos" (Rubio, 1994, p. 5). Esta ideia de única possibilidade ou de inevitabilidade é comum nos textos que tratam da globalização e que defendem um modelo de desenvolvimento nacional baseado em padrões de industrialização e em uma economia de mercado internacional, muito próxima às ideias de etapas de desenvolvimento que diferenciam "primeiro mundo" e "terceiro mundo" ou "países desenvolvidos" e "países subdesenvolvidos". Como já mencionamos, estes conceitos estavam baseados em teorias economicistas dos anos 1970 e foram usadas para criar um discurso teleológico acerca da globalização, permitindo que intelectuais como Rubio produzissem e circulassem estas concepções de que diante do global inexorável a única opção para o México era ceder ao neoliberalismo que submetia os interesses do país ao capital privado ou estrangeiro.

Outro texto, publicado em Vuelta, em maio de 1993, escrito por Guillermo Tovar de Teresa (1993), ${ }^{8}$ usa esta mesma concepção para atacar qualquer tentativa de resistência às reformas neoliberais no México. Segundo este autor, “es la 'globalización' que producirá la inevitable interdependencia económica, promisoria todavía de un futuro redentor" (p. 34) e, por causar transformações na economia e política, assustam os ignorantes e os que se aproveitam de privilégios num sistema ultrapassado. Este seriam os "fundamentalistas" que, avessos à globalização e à modernização, são uma ameaça ao país:

El verdadero riesgo del nuevo fundamentalismo mexicano lo podrían crear los temores irracionales que nos fabricamos desde que nos enteramos de la existencia de un Tratado de Libre Comercio con Estados Unidos y Canadá. [...] Riesgo inquietante de fundamentalismo lo ofrecen ahora las "comunidades". [...] En un aspecto, su existencia es alentadora: son las semillas de la democracia y la sociedad civil. En otro, son un riesgo: cuando pervierten el sentido de la sociedad civil para transformarse en batallones de la inercia, por el miedo al presente y sus realidades. [...] El futuro de la sociedad civil en México no debería degenerar en la existencia de células fundamentalistas, deseosas de la intervención estatal cumplidora de sus caprichos y defensora de sus temores

8 Tovar de Teresa foi um historiador e erudito mexicano, dedicado ao estudo da arte e patrimônio mexicanos. Precocemente, foi conselheiro aos treze anos de idade do presidente Gustavo Díaz Ordaz, no fim dos anos 1960, mas não ocupou nenhum cargo público durante o resto da sua vida. Atuou ativamente no Consejo de la Crónica de la Ciudad de México, desde 2007 até 2013. 
irracionales. Me refiero a las "comunidades" enemigas de cualquier proyecto que se atreva a modificar cualquier cosa, llámense sindicatos, asociaciones ecológicas o de vecinos (Tovar de Teresa, 1993, p. 39).

"Fundamentalismo" é o conceito desenvolvido neste texto para atacar qualquer crítica à globalização e ao neoliberalismo e desqualificar estas críticas como "temores irracionais" ou de uma esquerda que se aproveita da ignorância dos pobres. Como este trecho deixa explícito, as "células fundamentalistas", segundo o autor, são as associações de participação política popular ou de defesa dos trabalhadores. O discurso de "modernização" inevitável transforma-se, na argumentação de Tovar de Teresa, num elemento de divisão da sociedade mexicana entre aqueles que desenvolvem o país e aqueles que estão aferrados a moldes tradicionais de atraso e subdesenvolvimento. A questão da oposição à globalização é resumida a temores, ignorância ou má fé. $\mathrm{O}$ autor nem reconhece estes setores como grupos políticos porque, segundo ele, estão lutando contra o presente que já está em marcha e não são válidas suas demandas. Desta forma, quero demonstrar como a ideia de inevitabilidade em torno da globalização permitiu a produção de discursos conservadores simbolicamente violentos, capazes de desqualificar as ideias contrárias de participar do debate político. Assim como a globalização, discursivamente foi montada a inevitabilidade de reformas à Constituição de 1917 que, com suas garantias e direitos dos diversos grupos da sociedade mexicana, seria uma afronta ao futuro.

As propostas e concepções expressas nestes textos são exemplares de uma ideologia neoliberal conservadora. Estas concepções e argumentos em torno da globalização neoliberal (o papel mínimo do Estado, a necessidade de privatizações e a importância do capital estrangeiro no desenvolvimento econômico mexicano) estão presentes também em textos das outras revistas aqui estudadas, ainda que em posturas menos incisivas e radicais. Isso não significa que a globalização e o neoliberalismo foram tomados passivamente por todos os autores como a melhor solução econômica para o contexto político-econômico do México. Um bom exemplo de visão crítica sobre a globalização é um texto de Julio Labastida Martín del Campo, ${ }^{9}$ publicado na Revista de

${ }^{9}$ Labastida Martín del Campo é doutor em Sociologia pela École des Hautes Études en Sciences Sociales (EHESs), Francia. Pesquisador do Instituto de Investigaciones Sociales (IIS) da UNAM e membro do Sistema Nacional de Investigadores (SNI) do México. 
la Universidad, em dezembro de 1991, em um número cuja sessão monográfica traz vários textos sobre o tema da globalização.

O autor é direto ao descrever as consequências da globalização e seus processos: a degradação do meio ambiente, o perigo nuclear diante de um enorme arsenal atômico, a desigualdade crescente. Mais adiante no texto, enquanto reconhece os avanços importantes na ciência e tecnologia, afirma categoricamente o que a globalização acarreta sobre a integração das sociedades:

[...] con frecuencia la modernidad que acompaña a este progreso favorece el exceso de individualismo y racionalismo, es decir, el deterioro creciente de un ethos cultural que sea capaz de asegurar la unidad y el destino de la vida colectiva. No podríamos dejar de ver, sin cierta inquietud, la destrucción acelerada de la sociabilidad en las sociedades avanzadas; la desnacionalización de las grandes ciudades y el auge del racismo en sociedades que se han vuelto multiculturales; la indiferencia frente a la vida pública, convertida en un espacio puramente formal, de administración y gestión; la ausencia de participación social y el refugio creciente en la vida privada (Labastida Martín, 1991, p. 10).

Labastida Martín del Campo traz em seu texto, assim, uma visão não só de crítica, mas também de preocupação. Fica claro ao longo de sua argumentação que os processos em voga a partir da globalização tem efeitos políticos e sociais diretamente relacionados com os avanços da modernidade técnica e científica. Inclusive, segundo o autor, esta modernidade está sendo processada de forma desigual e segmentada, não estendendo a todos os setores das sociedades suas conquistas e desenvolvimentos, tornando-se, então, um fator de exclusão social. Uma das consequências disto, no contexto mundial de acirramento da desigualdade entre Norte e Sul, é o surgimento dos movimentos fundamentalistas no Oriente Médio: "La exclusión y la frustración de la mayoría de la población del planeta en sus aspiraciones de participar en los beneficios del desarrollo, han tenido como consecuencia movimientos de afirmación cultural en regiones del Tercer Mundo [...] que han roto los equilibrios precarios de paz" (Labastida Martín, 1991, p. 8).

Este texto, no entanto, é significativo porque traz uma proposta de "comunidade internacional" para conciliar os avanços positivos da globalização com políticas de democratização de seus benefícios. Através do desenvolvimento econômico mundial de todos os países por igual, os aspectos negativos da globalização seriam dissolvidos. O autor afirma que 
[...] la Humanidad en su conjunto tiene actualmente los medios científicos y técnicos para que cada vez más países puedan incorporarse a un desarrollo fuertemente sustentado a la vez en bases internas y en una sólida incorporación a una división internacional del trabajo más equitativa y racional. Ahora el desarrollo no puede entenderse ni contra ni al margen de la construcción de una verdadera comunidad mundial (Labastida Martín, 1991, p. 9).

O limite, ainda segundo o autor, para a formação desta comunidade, seria a distribuição desigual de riqueza e conhecimento que ocorre na globalização. A solução vislumbrada, de acordo com Labastida Martín del Campo, é a configuração de sínteses entre a cultura e a modernidade, sendo o cultural e suas especificidades locais uma possibilidade de resistência à esmagadora voracidade produtiva da economia globalizada. Desta forma, este artigo, soube identificar e descrever os problemas sociais e políticos da globalização neoliberal, arriscando uma proposta de usar o cultural para conter seus efeitos negativos.

Ainda nesta perspectiva crítica, posso destacar um artigo de Jaime Bautista Romer ${ }^{10}$ que descreve sistematicamente as características do neoliberalismo: liberalização irrestrita da economia, desemprego e subemprego, deterioração do nível dos salários e da qualidade de vida, concentração de renda, entre outras (Bautista Romero, 1997, pp. 13-15). O autor também ressalta um efeito mais perverso do neoliberalismo que é a descrença na vida coletiva e na política como meios de transformação social. Ou seja, além de todos os prejuízos já mencionados, a consciência política e a união social são deslegitimadas, o que reforça apenas a força voraz do capitalismo globalizante e neoliberal. A alternativa proposta por Bautista Romero (1997, pp. 16-17) se viabilizaria em uma reforma tributária, na criação de linhas de crédito do governo para o setor produtivo nacional, na intervenção do Estado que deve controlar a abertura da economia e definir critérios sociais para os gastos públicos.

Os textos de Labastida Martín del Campo e Bautista Romero, ainda que tragam uma leitura mais crítica da globalização, revelando fatores políticos deste fenômeno que estão presentes nas análises mais atuais deste processo, continuam reforçando sua inevitabilidade, elemento discursivo que, em outros textos já comentados, permitiu a construção de visões conservadoras que re-

${ }^{10}$ Bautista Romero é graduado em Economia pela UNAM. No momento da publicação deste texto, era professor da Facultad de Ciencias Políticas y Sociales e pesquisador do Instituto de Investigaciones Económicas, ambos da UNAM. 
cusam o debate com aqueles que se colocam em oposição a "modernização". Meu argumento, aqui, é que ainda que vislumbrassem alternativas de condução de um processo que se mostrava bastante negativo à sociedade mexicana ao longo dos anos 1990, estes textos não conseguiram superar em suas análises a ideia de uma globalização inexorável. As demandas destes textos por identidades culturais locais, intervenção do Estado ou reforma tributária, na verdade, propõem um sistema político e econômico muito próximo daquele que o próprio PRI vinha desmontando e reformando desde pelo menos os anos 1980.

Nesta análise sobre os temas da globalização, ficou evidente uma ampla variedade de posições e interpretações assumidas por esses intelectuais que superam os posicionamentos políticos declarados pelas revistas como, por exemplo, Nexos, de característica socialdemocrata e crítica às reformas neoliberais, publicando o texto de Luis Rubio, que defende a completa liberalização da economia mexicana. É importante destacar que as revistas não são monolíticas, fechadas e rígidas, e apesar de se declararem mais próximas a esta ou aquela ideologia, distintas posições apareceram em suas páginas porque o debate sobre a globalização era assim composto por uma amplitude de perspectivas de todo o espectro político. Estas publicações não eram representantes de partidos ou defensoras de uma ideologia e se comprometiam com a abertura a intelectuais e ideias que julgavam pertinentes naquele contexto, pertinência esta que se baseava menos em critérios políticos do que no aporte de suas argumentações ou mesmo no renome e reconhecimento dos autores no campo intelectual mexicano. Assim, buscavam promover uma discussão que abarcasse diferentes pontos de vista e nutriam um debate contínuo que não se esgotava a cada volume mensal, até porque era interessante para seu funcionamento editorial que a vigência dos debates fosse renovada a cada edição destas revistas publicada no país, revigorando o interesse dos leitores e consumidores no tema.

Desta forma, apesar da polifonia parecer indistinta e desconexa, é possível descrever eixos e transversalidades que conectam estas publicações num esforço de produção discursiva. Esta percepção é essencial para o estudo das revistas como fontes históricas. Ao entendê-las como objeto de investigação, o historiador leva em conta o fato de que as revistas responderam ao seu contexto e não são neutras (Crespo, 2010; 2011, pp. 98-102). Assim, participam dos debates não só como mero suporte material dos textos, mas também como uma rede de pontos de contato, sociabilidade e conexão entre diferentes sujeitos históricos: autores, editores, tradutores, ilustradores, etc. Os grupos 
intelectuais que se reuniram em torno de cada publicação encontraram aí, então, um espaço de expressão, mas também o conjunto de revistas serviu como referencial retórico para a construção de suas ideias e argumentos. Desse modo, as revistas fazem parte do ideário político de seu contexto em uma dinâmica de funcionamento duplo: transformam e são transformadas pelas discussões de que fazem parte, circulando discursos e ressignificando as linguagens políticas em debate na sociedade (Pita y Grillo, 2013).

No caso aqui analisado, os textos destas publicações apresentam a perspectiva de uma crise, econômica e política, constante no país, sendo a globalização vista tanto como problema quanto solução. Relacionando estes textos com as transformações que o PRI colocava em prática neste contexto, podemos compreender a importância que estes discursos tiveram para a conformação de um imaginário político propício às reformas neoliberais no México e, em consequência, de deterioração da configuração tradicional de Estado revolucionário fomentado ao longo do século xx.

\section{O GRUPO SAN ÁNGEL: DEMOCRACIA E "MODERNIZAÇÃO" EM DISPUTA}

Em 1994, um grupo de intelectuais organizou reuniões nas quais debateram os rumos da política mexicana e declararam-se em defesa da democracia. Composto por um amplo matiz de posições políticas, o Grupo San Ángel buscou formas de influenciar e impactar as mudanças políticas no país. Assinaram e divulgaram os "vinte compromissos pela democracia", mas ao fim das eleições daquele ano, com a vitória do PRI com Ernesto Zedillo, o grupo se diluiu. ${ }^{11}$ Quando se organizaram as reuniões, estes intelectuais já tinham seus nomes consolidados e tinham uma posição de prestígio como intelectuais públicos dedicados a debater as questões políticas, sociais, econômicas e culturais no país. Deste modo, este grupo nos apresenta a ideia de que intelectuais mexicanos muito conhecidos estavam mobilizando-se e tentando participar ativamente como uma força política nos processos eleitorais do país. Ainda que não tenham conseguido uma unidade duradoura, este esforço indica que compartilhavam de premissas políticas acerca do processo de transição democrática no México.

${ }^{11}$ G. Ochoa Sandy, "Alianza sin intelectuales”. La Jornada, 26 de septiembre de 1999. 
Buscando pelos textos publicados por estes intelectuais nas revistas aqui estudadas, fica evidente uma produção profícua por vários destes intelectuais e os diversos textos, publicados ao longo de toda a década de 1990, abordam distintos temas, mas as questões políticas e o debate sobre a democracia se sobrepõem. Assim, esta análise de alguns textos publicados antes e depois da criação do Grupo San Ángel busca apontar temas e argumentos para entender como alguns de seus membros mobilizaram discursos em torno das ideias de globalização, neoliberalismo, democracia e "modernização". Os textos aqui analisados são de autoria de Enrique Krauze, ${ }^{12}$ Carlos Monsiváis $^{13} \mathrm{e}$ Jorge Castañeda, ${ }^{14} \mathrm{e}$ não representam as ideias formuladas nas reunióes do grupo, mas nos permitem compreender como intelectuais de distintas posições políticas formularam interpretações de seu presente e como construíram discursivamente o processo de globalização e transição democrática nos anos 1990.

Em um texto de 1991, Enrique Krauze comenta as eleições estaduais, mais especificamente a derrota do PRI nos estados de Guanajuato e San Luis Potosí. O autor afirma que a democracia no México teve um grande avanço aquele ano, ainda que a presidência, todavia, fosse controlada pelo PRI. Descrevendo a situação política do país desde a década de 1970, Krauze afirma que o Estado priista, baseado em um forte presidencialismo, não teria mais opção a não ser aceitar que o processo de democratização já é parte da agenda política nacional. O texto também afirma que as forças cívicas que atuaram em Guanajuato e San Luis Potosí demonstram mudanças na sociedade mexicana para combater a concentração de poder do presidente. A crítica de Krauze aO PRI se processa em termos políticos de defesa da democracia e da necessidade de eleições legítimas, ainda que no aspecto econômico o autor

${ }^{12}$ Krauze é um renomado historiador e escritor mexicano, atualmente membro do El Colegio Nacional e da Academia Mexicana de la Historia. Sempre se identificou como liberal e polemista, constantemente fomentando a crítica ao PRI desde os anos 1980. Ativo colaborador de Octavio Paz na revista Vuelta e fundador da revista Letras Libres.

${ }^{13}$ Monsiváis estudou na Facultad de Economía e na Facultad de Filosofía y Letras da UNAM, e fez parte do Centro de Estudos Internacionais da Universidade de Harvard, nos anos 1960. Como jornalista colaborou em inúmeras publicações e defendeu em seus trabalhos posições políticas de crítica ao autoritarismo e conservadorismo. Seus ensaios e crônicas foram premiados diversas vezes em sua carreira. Faleceu em 2010.

${ }^{14}$ Castañeda é doutor em História pela Universidade de Paris e, no momento da publicação deste texto, era professor da Facultad de Ciencias Políticas y Sociales, da UNAM. Politicamente, atuou como assessor de Cuauhtémoc Cárdenas nas eleições de 1988 e de Vicente Fox na campanha de 2000. Entre 2000 e 2003, foi ministro de relações exteriores do governo de Fox. 
concorde com as reformas empreendidas nos últimos governos: "El mismo gobierno que con resolución, inteligencia y eficacia enfila al país hacia la modernidad económica, ha bloqueado el tránsito hacia la modernidad política. [...] Nuestras elecciones, además, se llevan a cabo en un marco profundamente inequitativo para los partidos de oposición, con los dados cargados -cargadísimos- a favor del prinosaurio" (Krauze, 1991, pp. 69-70).

O discurso da democracia seguramente é um ponto de inflexão o discurso de Krauze. Como o autor afirma, desde os anos 1970, o sistema político mexicano sofreu mudanças e sua argumentação destaca a atuação de partidos de oposição, como o PAN, no processo de democratização. No trecho destacado acima, é clara sua concepção dual em torno da ideia de "modernidade", sendo economia e política duas instâncias a serem "modernizadas" no México. As reformas neoliberais que vinham tomando forma no país são vistas positivamente por Krauze, como um exemplo de "inteligência" e "eficácia" do governo priista que, assim, "modernizava" a economia. Por outro lado, a "modernidade" política estaria sendo prejudicada pela resistência do governo em promover eleições transparentes e dificultar o processo de democratização no país. Desta forma, ao identificar democratização com a ideia de "modernidade" política, o texto traz o argumento de que o PRI é um obstáculo à democracia ao buscar manter-se no poder. As reformas neoliberais são celebradas como forma de legitimar um processo "modernizador" na economia e se convertem em crítica ao PRI por não promover na política um processo semelhante.

Assim, neste texto de Krauze, "modernização" e democracia se tornam elementos inseparáveis para que se efetive sua crítica ao sistema político mexicano e para que se constitua um projeto de nação baseado em uma "modernidade" dupla. Deste modo, o autor constrói um discurso que identifica o interesse do povo mexicano (democracia) e a liberalização da economia como faces de um mesmo processo "modernizador". A força de sua argumentação está no fato de que não deixa espaço para que se questione os benefícios ou danos que a economia de mercado traria à sociedade mexicana. Ao leitor não se apresenta uma análise mais ampla e profunda do conceito de "modernização", reproduzindo a ideia simplista de que se é moderno, é bom. Mais ainda, de acordo com o discurso do autor, criticar o processo de "modernização" é o mesmo que criticar a democracia.

Em outro texto, publicado na edição de julho de 1999 de Letras Libres, Krauze descreve a democracia no México como ainda "adolescente" porque não acredita que a população exerça todos seus direitos democráticos. $\mathrm{O}$ au- 
tor define democracia de duas formas: o processo de seleção transparente e justo dos líderes políticos e a vida em uma sociedade na qual a igualdade de direitos e as liberdades políticas dos indivíduos são preservadas. Krauze argumenta que uma democracia madura é importante porque aprofundaria os avanços políticos dos últimos anos para evitar problemas como: "recaída en el caudillismo populista, brotes de fundamentalismo contracultural, aislamiento económico en un mundo vertiginosamente globalizado, violencia política general y hasta intentos de secesión" (Krauze, 1999, p. 76). Segundo o autor, os atores que podem promover esta maturidade são: os candidatos nas eleições, os partidos políticos, o governo, os meios de comunicação e a sociedade civil. O texto descreve seus papéis definidos em termos de justiça social e participação política em todos os níveis do sistema mexicano, de modo a garantir que a democracia seja exercida plenamente.

Mas o interessante aqui é perceber como os discursos sobre a democracia são mobilizados neste contexto, em fins dos anos 1990. A crítica aos governos do PRI se mantém neste texto quando Krauze (1999) afirma que "nuestra historia nos preparó para simular la democracia, no para ejercerla" (p. 76). Mas é inegável que as reformas eleitorais promovidas pelo PRI responderam às principais demandas do processo de transição e Krauze aceita que a democracia está em desenvolvimento neste período no México, ainda que seja "adolescente". Utilizando a ideia de "adolescência" para definir algo incompleto, a democracia mexicana, de acordo com o texto, estaria em risco de converter-se em populismo, fundamentalismo, isolamento econômico, violência e secessão.

É com este argumento que Krauze mobiliza a ideia de "globalização vertiginosa" que, como a ideia de "globalização inexorável", já discutida aqui, é categoria discursiva constante no processo de reformas neoliberais do México. Assim, a democracia como concretização da "modernidade" política esteve discursivamente associada à globalização. Este texto, ainda que seja escrito em um contexto político marcadamente distinto do início dos anos 1990, revela que democracia e globalização ainda eram categorias discursivas relacionadas estritamente. Krauze busca sugerir caminhos e práticas sociais de participação política e, ao fazê-lo, revela que um dos objetivos da democracia, em sua concepção, é garantir a participação do México no mundo globalizado. A demanda por reformas não está presente neste texto porque, em 1999, as reformas econômicas e políticas já haviam se processado, mas a alternância ainda não havia se concretizado. Ao associar novamente democracia e globa- 
lização, o autor sustentou os mesmos discursos que justificavam a neoliberalização nos anos 1980 e princípio dos anos 1990.

Carlos Monsiváis descreve, em 1990, o ambiente político no México à luz da mobilização política desde as polêmicas eleições de 1988. Publicado cerca de um ano depois da posse de Carlos Salinas, este texto ironiza o otimismo político em torno das reformas econômicas do novo governo, num processo onde distintos atores se empenhavam num esforço de propaganda do neoliberalismo. Monsiváis indica o uso do conceito de "modernização" como argumento de convencimento e de união da elite em torno a um projeto que deveria mudar a identidade nacional, a "essência" mexicana:

Por lo pronto, el sistema político ha probado sus minúsculas posibilidades de cambio. El Presidente lanza la consigna: "Modernización", y de inmediato recibe [...] el alud retórico de los conversos, ayer revolucionarios aposentados en la Identidad Nacional, hoy modernos, modernizados y modernizadores. [...] Los excesos que antes se veían como encantamientos rituales ("Detente, Reacción") hoy son tributos al fuego nuevo de la negación de todo el pasado gubernamental a nombre de la posesión del futuro. Sin rubor, y a nombre de los gobernadores, el de Jalisco, Guillermo Cosío Vidaurri, afirma ante el mismo Presidente, que en los once meses de su mandato, han cambiado "el rostro y la esencia" de México (Monsiváis, 1990, p. 1).

Neste sentido, percebe-se que o discurso de "modernização" foi utilizado com propósitos políticos sem muitas definições, atuando discursivamente como uma generalização que daria conta de distintos interesses de diferentes grupos políticos mexicanos. $O$ autor denuncia a estratégia política de utilizar a ideia de "moderno" para promover as mudanças econômicas da nova administração:

Y las únicas propuestas tajantes (la reducción del Estado, la apertura de la economía, la integración creciente con Norteamérica), han sido velozmente trasladadas al idioma incomprensible de la corte política, donde todo es logro y nada es explicación. Y los integrantes del sistema son los primeros en banalizar, con enredijos verbales, un proyecto que, para mí, tiene puntos muy atendibles y una perspectiva general que si no es neoliberalismo, se le parece mucho en lo que presupone: el arrinconamiento de las mayorías "no modernizables", la instauración institucional de dos países con el mismo nombre, la 
justicia social que se predica con tono no muy convincente, devastada por el sometimiento al capitalismo más bárbaro (Monsiváis, 1990, p. 2).

Assim, é importante destacar como o texto de Monsiváis atrela explicitamente o processo de "modernização" mexicano ao neoliberalismo através das reformas do governo de Carlos Salinas, vislumbrando consequências como o país submetido ao capitalismo internacional e sem garantias de justiça social. Ainda que, de acordo com o autor, o PRI e o grupo do governo não utilizem as definições de neoliberalismo para se referir a tais reformas, é inegável que a economia mexicana estava sendo transformada neste sentido.

Deste modo, por uma perspectiva distinta e com intento óbvio de denúncia, Monsiváis utiliza este texto para aclarar a definição política que se impunha ao conceito de "modernização", revelando seus efeitos negativos. Entre os efeitos mais danosos, está o da despolitização: "Para consolidar su acción, el gobierno impulsa y coordina degradación del impulso cívico y de la política (con el apoyo entusiasta, por involuntario que sea, de núcleos del PAN y del PRD). De nuevo, y con tal de negar las elecciones de 1988 afianzar el triunfalismo de ocho columnas de 1989, se fomenta la despolitización" (Monsiváis, 1990, p. 2). O autor acrescenta que os avanços democráticos são reais e nem tudo se perde em manipulação política, mas sua crítica é importante. Ao criticar o uso da "modernização" como projeto velado do neoliberalismo, o autor expõe um processo de convencimento baseado em generalizações e em padrões discursivos reproduzidos por grupos políticos dominantes. As consequências afetam diretamente a democracia porque a participação política das "mayorías no modernizables" é indesejável para a "modernização" que se concretizava no neoliberalismo. Monsiváis criticava, então, não somente o discurso vazio de modernidade, mas também a tentativa consciente de despolitização, valorizando a democracia como possibilidade de atuação e defesa dos interesses da sociedade no México. Ainda que crítico à ideia de "modernização", o autor argumenta pela importância da democratização, desatrelando os dois processos. Krauze, como exposto, promovia uma conexão imediata entre "modernização" e democracia. Este texto de Monsiváis inverte esta relação, argumentando que a "modernidade" proposta nas reformas econômicas de Salinas eram a antítese da politização e, consequentemente, da democracia mexicana. Deste modo, fica evidente que estes discursos e categorias discursivas foram mobilizados por distintos atores com variados interesses. A importância de se estudar estes conceitos está precisamente na análise de como 
estas ideias foram utilizadas e como circularam no ideário político mexicano neste contexto de globalização neoliberal.

Em um debate publicado por Nexos, em 1998, os intelectuais Jorge Castañeda, Héctor Aguilar Camín ${ }^{15}$ e Rolando Cordera ${ }^{16}$ abordam o tema da globalização e a relação que se estabelece com as políticas neoliberais. A transcrição da conversa entre os autores se converte em um texto no qual propõem e discutem possibilidades e alternativas ao neoliberalismo frente a seus efeitos negativos, como dependência econômica e empobrecimento da população. Os autores partem de questões muito significativas de sua perspectiva sobre as reformas colocadas em prática no México durante os anos 1990: ¿¿Hacia dónde vamos en el mundo que convenimos todos en definir o describir como un mundo global y globalizado? ¿A dónde nos llevan las políticas que se han puesto en práctica a partir sobre todo de la gran crisis internacional de la deuda y que se resumen en el vocablo neoliberalismo? ¿Hay alternativas para ellas?" (Castañeda, Aguilar Camín y Cordera, 1998, p. 1).

Estas perguntas, além de definirem o tema do debate em torno à possibilidade de alternativa ao neoliberalismo, assinalam uma abordagem problematizadora ao tratar o "mundo global y globalizado" como uma convenção discursiva e o neoliberalismo como vocábulo. Esta perspectiva é muito importante porque permite aos autores criarem seus argumentos entendendo que globalização e neoliberalismo são conceitos e, como tais, não têm um significado único ou uma definição fechada a interpretações. Castañeda revela que a ideia de discutir alternativas ao neoliberalismo busca questionar a relação que é tomada como natural entre globalização e neoliberalismo:

Creo que el enigma y la complicación reside justamente en esta relación de sinónimos que se ha establecido entre globalización y neoliberalismo. Lo que se ha querido plantear en este esquema del "pensamiento único", de "consenso de Washington" o como se le quiera llamar, es que frente a la globalización, que es un proceso real, no hay más alternativa de política pública que el llamado neoliberalismo, siendo que en realidad uno puede perfectamente, $y$

${ }^{15}$ Aguilar Camín é historiador, escritor e jornalista. Possui doutorado em História pelo El Colegio de México, é conhecido por suas obras de ficção e sua atuação como colaborador de distintas publicações.

${ }^{16}$ Cordera é formado em Economia pela UNAM com pós-graduação na Inglaterra. Colaborador de diferentes periódicos, era director da Nexos TV nos anos 1990. É pesquisador do SNI desde 2002. 
es lo que hace Mangabeira, escindir los dos términos, separarlos (Castañeda, Aguilar Camín y Cordera, 1998, p. 2).

Cordera também expressa este questionamento sobre a realidade efetiva de um mundo globalizado estar atada ao neoliberalismo:

La elaboración de alternativas de debate de fondo en México, en América Latina y en el mundo, no pasa por la negación de la realidad, no pasa por olvidarnos de ella, y esta realidad es la globalización, pero tampoco pasa necesariamente por la aceptación unánime, resignada, de lo que se ha dado en llamar el pensamiento único y que se llamó en un tiempo el "consenso de Washington" (Castañeda, Aguilar Camín y Cordera, 1998, p. 13).

Nestes trechos está clara a ideia de que, como termos, globalização e neoliberalismo são tomados como sinônimos em discursos que defendem os interesses do capitalismo global o estadunidense. O Consenso de Washington, como formulação oficial do Fundo Monetário Internacional (FMI) nos anos 1990, foi uma ferramenta de prescrição de ajustes macroeconômicos aos países que adotavam o neoliberalismo. $\mathrm{O}$ argumento de Castañeda reside precisamente na ideia de separar os termos, não considerando-os equivalentes e permitindo que se conceitualize um mundo globalizado e não-neoliberal. As bases da discussão que se dá neste texto estão assentadas, então, na possibilidade de pensar a globalização e o neoliberalismo como categorias discursivas capazes de estabelecer relações materiais com a realidade do México.

Pode-se realizar uma leitura muito proveitosa das ideias propostas neste debate sobre regulação e o papel do Estado mexicano nos processos de globalização, mas meu foco está em como discursos e conceitos foram mobilizados pelos autores. A dimensão simbólica em torno destes termos é essencial para que proponham uma outra realidade política e econômica. Além de revelar que, nos anos 1990, o discurso dominante criou uma equivalência entre neoliberalismo e globalização, os autores se propõem discutir e projetar um país diferente no futuro. Ao argumentar que neoliberalismo e globalização são discursos construídos intencionalmente como correlações reais e materiais, os autores criam junto a seus leitores uma perspectiva de que novos significados podem ser atribuídos a políticas públicas de desenvolvimento e, assim, a globalização não tem que necessariamente representar empobrecimento ou aumento da desigualdade. 
Em outro artigo, de 1993, Castañeda já discutia com Carlos Heredia ${ }^{17}$ sobre o NAFTA, então em processo de negociação e ainda não ratificado. Os autores assumem a tarefa de analisar o acordo econômico a partir da perspectiva de como se definiram os debates em torno a este processo. $O$ texto destaca a necessidade de uma abordagem do NAFTA que dê conta de "sus costos y beneficios, que analizara las alternativas posibles y los postulados conceptuales implícitos. Hasta ahora ese debate no se ha dado. Con algunas excepciones, siguen ausentes dos discusiones esenciales sobre el acuerdo: el problema de su inevitabilidad, y el de la gama de variaciones en el que está inserto" (Castañeda y Heredia, 1993, p. 1). Deste modo já fica clara a premissa de que o NAFTA está relacionado com a realidade material dos mexicanos, em "seus custos e benefícios", mas também tem uma dimensão simbólica de significados em seus "postulados conceituais". Os autores iniciam, assim, uma discussão muito pertinente sobre como as negociações do acordo se difundiram na opinião pública mexicana e quais os usos que os políticos estavam fazendo destes discursos.

O tema da inevitabilidade é parte importante do argumento dos autores sobre como se produziram e circularam os discursos do NAFTA: "se da casi por sentado que la noción de inevitabilidad es consustancial al acuerdo como tal. Se puede uno lamentar de que haya un acuerdo, o congratularse de ello, pero pareciera que -con algunas contadas excepciones- todo el mundo acepta su carácter inevitable" (Castañeda y Heredia, 1993, p. 2). Os autores descrevem três graus de integração na América do Norte de modo a definir uma ordem decrescente de inevitabilidade: a integração comercial com os Estados Unidos, a formalização deste comércio e, por fim, o NAFTA. Deste modo, ao discutir o que significa "inevitabilidade" neste contexto mais amplo, os autores revelam que, ao tratar o NAFTA como inevitável, se reproduz um discurso que tem mais a ver com as relações econômicas entre os dois países, e não tanto com este acordo especificamente. Assim, o uso da ideia de inevitabilidade como legitimação do NAFTA é desmontado e denunciado no texto:

La confusión de los tres mencionados grados de inevitabilidad le ha permitido al gobierno de México, y al de George Bush en menor medida, plantear una

${ }^{17}$ Carlos Heredia é pesquisador do Centro de Investigación y Docencia Económicas (CIDE), no México. Formado em Economia pelo Instituto Tecnológico Autónomo de México (ITAM), tem mestrado e doutorado na mesma área. Atuando politicamente, foi deputado federal pelo PRD, entre 1997 e 2000. 
falsa alternativa en la que han caído casi todos los sectores de opinión. Consiste en la dicotomía siguiente: "o este acuerdo o la autarquía". Como nadie puede optar por la autarquía, resulta imperativo pronunciarse a favor de este acuerdo. El sofisma funciona igualmente al revés: quienes se oponen a este acuerdo proponen la autarquía. Es falso que la única alternativa al acuerdo de Bush y Salinas sea la autarquía, el proteccionismo o el regreso al statu quo ante. [...] En realidad, la verdadera elección que se le presenta al país consiste en escoger entre el acuerdo ya negociado, es decir, un acuerdo de derecha, de corte neoliberal y republicano, y un convenio de otra naturaleza, más bien socialdemócrata, con una fuerte dosis de regulación y de planeación, inspirado en lo que sería un liberalismo socialdemócrata de la nueva América del Norte. El contraste entre estos dos acuerdos refleja la diferencia o la oposición que impera hoy en día entre los capitalismos que existen en el mundo (Castañeda y Heredia, 1993, p. 3).

$\mathrm{O}$ argumento dos autores está baseado, desta forma, em expor as implicações materiais de uma construção discursiva e simbólica. Ao aceitar o NAFTA como inevitável, se aceita a economia de mercado, a desregulação e as privatizações como os únicos termos nos quais é possível formalizar a integração com os Estados Unidos. Esta concepção, de acordo com Castañeda e Heredia (1993, pp. 4-5), tem um propósito muito claro no discurso oficial dos governos que é o de evitar questionamentos e promover a aceitação incondicional do NAFTA. Ao revelar esta estratégia discursiva como um sofisma, os autores estão argumentando que o neoliberalismo necessitava de legitimação simbólica e não somente política. O governo de Salinas não conseguiria impor as reformas autoritariamente, buscando, então, discursos favoráveis ao seu projeto para constituir um processo de convencimento. Ao fechar o debate em termos duais da oposição NAFTA versus autarquia, este tipo de discurso eliminou a discussão de alternativas e possibilidades de desenvolvimento integrado, como as propostas indicadas pelos autores de um liberalismo socialdemocrata. Ainda segundo os autores, o discurso do governo mexicano simplifica um debate muito mais complexo sobre os capitalismos do mundo e as formas de desenvolvimento que buscam evitar os problemas sociais do neoliberalismo.

Todo o artigo discute modos de criar-se um bom acordo para o México com as fortes economias do Canadá e Estados Unidos, mas o tema da legitimação é imperativo. Os autores expõem como este processo de construção discursiva criou uma limitação real das condições em que se processava O NAFTA: 
Existe pues una alternativa viable, razonable y coherente para México. Se puede discrepar de su intencionalidad, de su inspiración ideológica y de sus posibles efectos. Pero su misma formulación -y la adhesión que pueda suscitar- muestra que la tesis central del gobierno mexicano, a saber, que no hay más opción que un acuerdo, y que el único acuerdo posible y concebible es el que dicho gobierno ha negociado, es falsa (Castañeda y Heredia, 1993, p. 21).

Este texto é significativo de uma argumentação contrária aos termos neoliberais do NAFTA e é revelador que a argumentação dos autores seja baseada em discutir a dimensão discursiva do processo de convencimento empreendido pelo governo mexicano. Os discursos sobre o neoliberalismo são mobilizados em uma leitura que os considera como elementos simbólicos com propósitos claros de legitimação e fechamento do debate em termos limitados. Este artigo de Castañeda e Heredia, de 1993, realiza a mesma operação argumentativa de outros textos aqui analisados, como o de Monsiváis (1990) e o do próprio Castañeda junto a Aguilar Camín e Cordera (1998). Ao propor o debate em termos narrativos e simbólicos, entendendo neoliberalismo, globalização, "modernização", democracia, entre outros como artefatos discursivos, estes textos criaram seu argumento de questionar os rumos do processo de liberalização e reforma no México dos anos 1990. Como se verificou nos textos de Krauze, estes discursos também foram mobilizados, mas foram naturalizados e tomados como monolíticos.

Deste modo, fica evidente a importância do simbólico em textos de autores que se propuseram a fazer uma crítica do processo mexicano de reformas políticas e econômicas nos anos 1980 e 1990. Como se percebe nestes artigos, no México não se buscou apenas examinar os avanços e efeitos negativos do neoliberalismo, mas também procurou-se propor alternativas que dessem conta das necessidades de todos os setores da população mexicana. Ao argumentar a partir desta perspectiva, os intelectuais teceram uma abordagem baseada na análise de elementos discursivos em seus múltiplos significados e interpretações, apontando para usos políticos destas narrativas e para a importância de uma visão mais ampla sobre os termos do debate. Assim, discursos como globalização, neoliberalismo, democracia e modernidade formaram parte do ideário político e do vocabulário intelectual no México deste contexto. Distintas perspectivas que circularam nestas revistas mobilizaram estes conceitos para construir suas posições, mas a forma como cada autor utilizou estas ideias e noções é representativa de seu argumento. Por 
um lado, ao reivindicar uma definição mais ampla destes conceitos, criou-se a possibilidade de se problematizar o processo neoliberal e criticar a economia de mercado como solução para os problemas do país. Por outro, ao fechar o debate em definições monolíticas e relações excludentes, promoveu-se a fórmula neoliberal, como o fizeram o governo e os discursos dominantes a favor da implantação do NAFTA. O que é mais importante de se destacar, então, é como os processos de globalização e transição democrática tornaram-se reais tanto em uma esfera material, composta por leis, reformas e acordos econômicos, quanto numa simbólica, através de práticas discursivas de legitimação e convencimento.

\section{CONCLUSÕES}

Estes textos analisados neste trabalho foram publicados quando ainda se processavam os projetos e medidas neoliberais na economia do país e, mesmo que os autores estivessem escrevendo e analisando seu presente, sem a consciência que temos hoje sobre estes processos, não deixam de demonstrar a importância que o tema da globalização teve no discurso intelectual do período.

A consciência de um cenário de crise constante despertou nestes intelectuais a ideia de que somente a economia global seria a solução para o "atraso" mexicano frente aos outros países da América e do mundo. No cenário de crise dos anos 1980 e de aprofundamento das reformas nos anos 1990, o processo de globalização, nos termos de uma abertura irrestrita neoliberal, portou uma aura de inevitabilidade no imaginário político da sociedade mexicana. A ideia de "modernização" política e econômica, que também se desenvolveu neste contexto discursivo, fez parte das discussões sobre democracia e transição. As disputas sobre a definição do que é ser "moderno" ou o que é viver uma democracia revelaram usos políticos de conceitos e termos que circularam nas páginas de revistas e foram mobilizados por intelectuais que buscavam elaborar explicações sobre o presente do México a partir de distintos posicionamentos.

Este trabalho focou-se justamente na tarefa de abordar os discursos produzidos por intelectuais, relacionando-os a um referente linguístico mais amplo, tal como orienta a metodologia de análise do pensamento político proposta por Pocock (2003). Para usar seus termos, a langue definiu não só o imaginário político mexicano, como também pautou os referenciais que per- 
mitiam a elaboração, mobilização e circulação de discursos que se efetivaram em textos, conceitos, termos e argumentos (parole). Estes elementos discursivos ganham sentidos e significados mais sofisticados quando inseridos neste contexto no qual as revistas e seus artigos eram um dos meios de expressão do campo intelectual mexicano. A importância de se estudar os discursos e as práticas intelectuais reside justamente na potência que estas análises oferecem para explorarmos a ação política destes sujeitos a partir de seus ofícios como criadores e mediadores culturais. Este entrecruzamento da história intelectual da política e da história política dos intelectuais surge, então, como forma de abordar e aprofundar os estudos sobre a história recente do México e seu ambiente político no período da transição democrática do fim do século xx.

\section{LISTA DE REFERÊNCIAS}

Babb, S. L. (2001). Managing Mexico: Economists from nationalism to neoliberalism. Princeton: Princeton University Press.

Bartra, R. (2013) The Mexican transition: Politics, culture, and democracy in the twenty-first century. Cardiff: University of Wales Press.

Bautista Romero, J. (1997) Estado y mercado en México. Revista de la Universidad, 560561, 13-17.

Bonanno, A., Martínez Gómez, F. y Aboites Manrique, G. (2016). El neoliberalismo, un momento de la globalización. México: Fontamara.

Camp, R. A. (1981). Intellectuals: Agents of Change in Mexico? Journal of Interamerican Studies and World Affairs, 23(3), 297-320.

Castañeda, J. y Heredia, C. (1993). Hacia otro TLC. Nexos, 181.

Castañeda, J., Aguilar Camín, H. y Cordera, R. (1998). Globalización y neoliberalismo. Nexos, 251.

Castillo, D. A. y Stuart, A. D. (eds.) (2014). Mexican Public Intellectuals. New York: Palgrave Macmillan.

Clavijo, F. y Valdivieso, S. (2000). Reformas estructurales y política macroeconómica. En F. Clavijo (ed.). Reformas económicas en México, 1982-1999. México: FCE/CEPAL.

Concheiro, L., Rodríguez, A. S. y Ruiz Rodilla, Á. (2018). Las décadas de Nexos (19781997) (T. I). México: Fondo de Cultura Económica.

Crespo, R. (ed.) (2010). Revistas en América Latina: proyectos literarios, políticos y culturales. México: UnAm/Eón. 
Crespo, R. (2011). Revistas culturais e literárias latino-americanas: objetos de pesquisa, fontes de conhecimento histórico e cultural. En S. M. Franco y M. A. Junqueira (eds.), Cadernos de Seminários de Pesquisa (pp. 98-115). São Paulo: Usp/Humanitas.

Dion, M. (2009). Globalization, democracy, and Mexican welfare, 1988-2006. Comparative Politics, 42(1), 63-82. DoI: https://doi.org/10.5129/001041509X12911362972836

Flores, M. (2010). Un cuartel general hispanoamericano. Inicio y consolidación de la revista Vuelta (1976-1998). En R. Crespo (ed.), Revistas en América Latina: Proyectos literarios, politicos y culturales (pp. 503-536). México: UNAM/Eón.

Gallegos Cruz, C. (2018). La escritura de la democracia: un estudio sobre las transformaciones de lo político y los discursos intelectuales en las revistas Vuelta y Nexos (1976-2000). (Tesis de maestría inédita). Instituto Mora, México.

Gutiérrez Pérez, A. (1991) La globalización económica: alcances y límites. Revista de la Universidad, 491, 12-14.

Justificación (1946). Revista de la Universidad, 1(1), 1.

Krauze, E. (1991). Balance político. Vuelta, 180, pp. 68-70.

Krauze, E. (1999). La democracia adolescente. Letras Libres, 7, 76-77.

Labastida Martín, J. (1991). Globalización, cultura y modernidad. Revista de la Universidad, 491, 8-11.

Mize, R. y Swords, A. (2011). Consuming Mexican Labor: From the Bracero Program to NAFTA. Toronto: University of Toronto Press.

Monsiváis, C. (1990) El pasado es el único país en crisis. Nexos, 145.

Pita, A. y Grillo, M. del C. (2013). Revistas culturales y redes intelectuales: una aproximación metodológica. Temas de Nuestra América, 29(54), 177-194.

Pocock, J. G. A. (2003). Linguagens do Ideário Político. São Paulo: Edusp.

Rubio, L. (1994). La política mexicana vs. la economía global. Nexos, 201.

Sánchez, L. C. (25 de enero, 2013). La Revista de la Universidad de México digitaliza historia literaria. Excelsior.

Sheppard, R. (2016). A persistent revolution: History, nationalism, and politics in Mexico since 1968. Albuquerque: University of New Mexico Press.

Sirinelli, J.-F. (2003). Os intelectuais. En R. Rémond (ed.). Por Uma História Política. Rio de Janeiro: FGV.

Solares, I. (2010). La Revista de la Universidad. Revista de la Universidad, nueva época, 79, 81-85.

Tovar de Teresa, G. (1993). México entre el fundamentalismo y la globalización. Vuelta, 198, 33-40.

Woldenberg, J. (2012). Historia mínima de la transición democrática en México. México: El Colegio de México. 